\title{
Development of real-time monitoring of alkaline phosphatase (ALP) biomarker released from cells based on microelectrode arrays for clinical analysis
}

\author{
Thanih A. Balbaied ${ }^{1}$, Walter Messian², Eric Moore ${ }^{2}$ \\ 12 University College Cork, Tyndall National Institution, Cork, Mardyke St, Ireland, \\ thanih.balbaied@tyndall.ie
}

\begin{abstract}
Alkaline phosphatase (ALP) biomarker is a membrane-bound enzyme widely distributed in the tissues of living organism. Abnormal level of ALP indicates diseases such as liver dysfunctions, bone disorders, ulcerative colitis, acute kidney injury and can diagnose cancer at early stage. There is thus a demand for a reliable technique to accelerate the sensing of ALP in point-of-care applications. Such methods although sensitive are costly process, and based on optical detections, which hard to be miniaturized. This work presented shows a method that integrates cell culture and electrochemical techniques to develop real-time detection of monitoring ALP released from cells.
\end{abstract}

Key words: Alkaline phosphatase, cell viability, microelectrode arrays, impedance, electrochemical sensor.

\section{Introduction}

The purpose of our work is to develop an electrochemical method that will pave the way to perform direct, cost effective, simple, monitoring of ALP biomarker from release in cells for point-of-care applications. Our approach is to integrate cell culture and electrochemical techniques to develop real-time detection of monitoring ALP released from living cells. The integration of these techniques can enhance the detection of biological targets based on the electrochemical change of electrode interfaces.

Our integrative approaches will take advantage of microelectrode arrays technology, facilitating the yield of recordings, signal shape, and signal-to-noise ratio. Electrochemical impedance devices, has 40 electrodes distributed in 8 wells that allow continuous visualisation of cell adhesion, spreading, proliferation, and detachment. Amperometric sensor has three-electrode system to monitor cellular signal transduction under a monolayer of cell culture conditions. The amperometric sensor application offers solutions that can be used in screening cellular ALP expression detected by electroactive species and hence avoid, radioactive, antibodies, mRNA tools that are presently used in clinics.

By optimizing impedance and amperometric parameters that investigate the cells confluence and concentrations of ALP, we hope to obtain sufficient real-time monitoring of ALP under cellular behavior in which provide a huge data for designing a portable prototype sensor for monitoring ALP from release in cells. The concentration will be compared to those available in state-of-the-art literature and shown in Table 1. It will present a linear range between the concentration of ALP and number of viable cells. Optimal results will be conducted with the patch clamp techniques. To the extent of our knowledge, few experiments is so far available on real-time monitoring ALP level in microelectrode arrays technology.

Tab. 1: Table literature reviews

\begin{tabular}{|c|c|c|c|}
\hline Methods & $\begin{array}{c}\text { Linear } \\
\text { Range } \\
\text { U/L }\end{array}$ & $\begin{array}{c}\text { Limit of } \\
\text { Detectio } \\
\mathbf{n} \text { U/L }\end{array}$ & Ref. \\
\hline Fluorescent assay & $\begin{array}{c}3.0- \\
27.0\end{array}$ & 0.19 & {$[1]$} \\
\hline Colorimetric assay & $1.5-20$ & 0.78 & {$[2]$} \\
\hline $\begin{array}{c}\text { Chemiluminescence } \\
\text { assay }\end{array}$ & $2-25$ & 2 & {$[3]$} \\
\hline $\begin{array}{c}\text { Photoelectrochemical } \\
\text { assay }\end{array}$ & $\begin{array}{c}3 \times \\
10^{-4}-1\end{array}$ & 0.0001 & {$[4]$} \\
\hline $\begin{array}{c}\text { Electrochemical } \\
\text { assay }\end{array}$ & $1-500$ & 0.5 & {$[5]$} \\
\hline
\end{tabular}

\section{Cell Viability Optimization}

For cells growth, media is mixed with supplements, which affect fluorescent signal shifts. The cells density affected by working 
area as well. Chosen the optimal density of cells that can stand the microtiters 4 days are performed and shown in figure 1. Reszurin needs several hours to be reduced to resorufin.

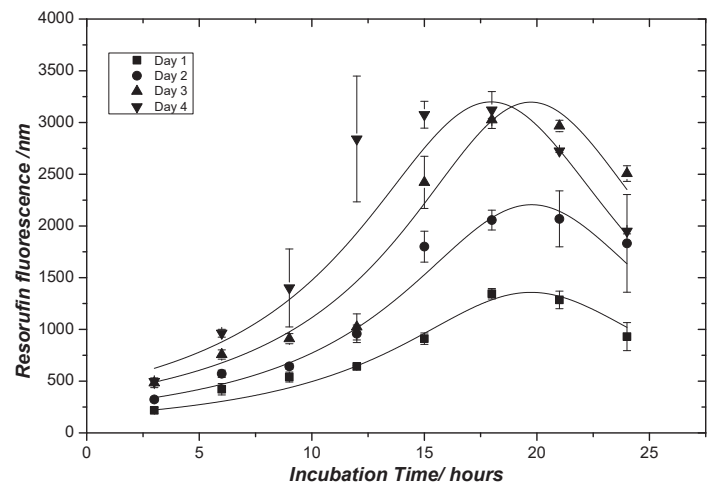

Fig. 1. Graph of resazurin reduction vs serial incubation time for 4 days at cell density of $80 k$ cell/ml.

\section{ALP measurements}

To investigate secreted ALP enzyme levels in the living cells, calibration experiments are conducted. Figure 2. Shows the optimal concentration of ALP. Figure 3 shows the optimal concentration of substrate.

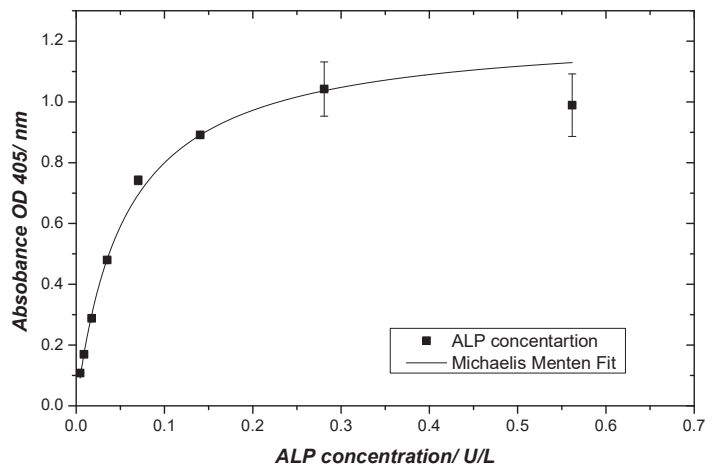

Fig. 2. Michaelis-Menten saturation of absorbance density vs serial concentration of ALP.

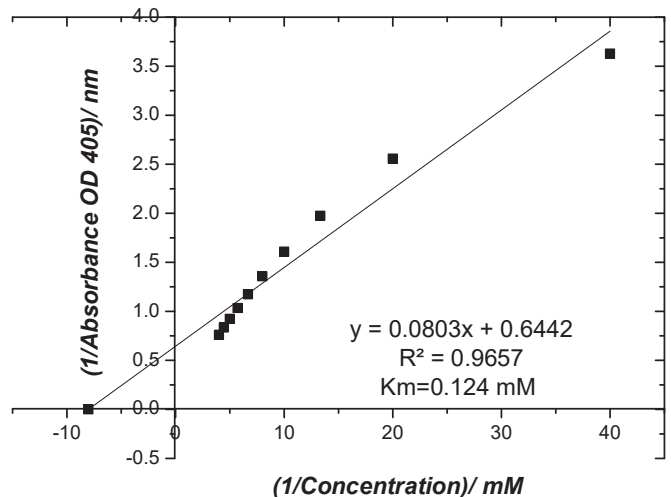

Fig. 3. Lineweaver-Burk plot of absorbance density vs serial substrate concentrations.

\section{Cell-Substrate Impedance Sensor}

impedance cell-based biosensor assays are performed in (electrde). Fibroblast cellsBalb/c3T3 at the optimal density $80 \mathrm{~K}$ cells $/ \mathrm{ml}$ are seeded on a microelectrode surface of 0.8 $\mathrm{cm}^{2}$.

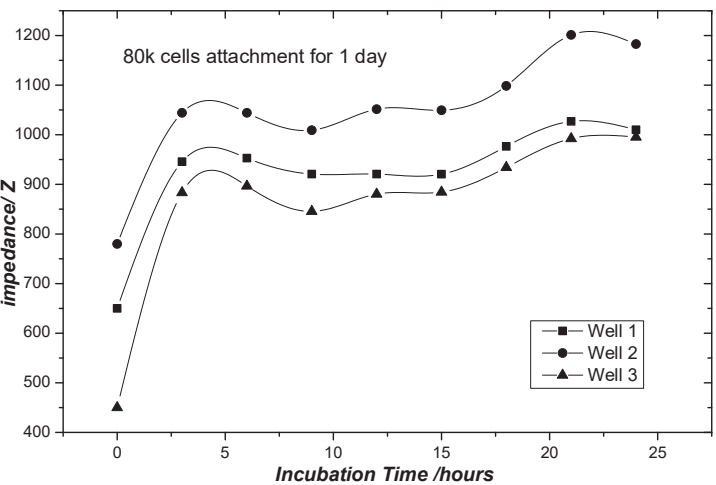

Fig. 4. Preliminary data of impedance at 8000 $\mathrm{Hz}$ frequency vs incubation time of $80 \mathrm{k} \mathrm{cell} / \mathrm{ml}$ and monitored for one day.

\section{Future work}

Preliminary data of microelectrode arrays need to be repeated. Quantity of secreted ALP need to be correlated with cell density. Amperometric optimization will be then conducted and compared to those of optical results. Shifts of current $(\mathrm{nA})$ in amperoemtric detection will be compared to those in patch clamp techniques.

\section{Acknowledgement}

My sincere thanks goes to Saudi Ministry of Education for sponsoring my study.

\section{Conclusion}

In our opinion the method with the ability of detecting ALP level directly with an inexpensive detection tool will ultimately be the future of point of care applications.

\section{References}

[1] L. Xue-Guo et al., Fluorescent assay for alkaline phosphatase activity based on graphene oxide integrating with $\lambda$ exonuclease. Biosensors and Bioelectronics 81, 460-464 (2016); doi: 10.1016/j.bios.2016.03.030.

[2] X. Chen et al., Colorimetric Detection of Alkaline Phosphatase on Microfluidic Paper-based Analysis Devices. Chinese Journal of Analytical Chemistry 44, 591-596 (2016); doi: 10.1016/S1872-2040(16)60923-4.

[3] H. Jiang et al., Alkaline phosphatase-responsive anodic electrochemiluminescence of CdSe nanoparticles. Analytical Chemistry 84, 6986-6993 (2012); doi: 10.1021/ac300983t.

[4] Q. Kang et al., Sensitive detection of ascorbic acid and alkaline phosphatase activity by double-channel photoelectrochemical detection design based on g-C3N4/TiO2 nanotubes hybrid film. Sensors and Actuators B: Chemical 230, 231-241 (2016); doi: 10.1016/j.snb.2016.02.059.

[5] C. Shen et al., A single electrochemical biosensor for detecting the activity and inhibition of both protein kinase and alkaline phosphatase based on phosphate ions induced deposition of redox precipitates. Biosensors and Bioelectronics 85, 220-225 (2016); doi;10.1016/j.bios.2016.05.025. 